\title{
Analisa perpindahan panas pada dies squeeze casting
}

\author{
Mafruddin $^{1^{\star}}$, M. Nur Iskandar², Dwi Irawan ${ }^{3}$ \\ 1,2,3JurusanTeknik Mesin,Fakultas Teknik, Universitas Muhammadiyah Metro \\ Jl. Ki Hajar Dewantara 15 A Kota Metro, Lampung, Indonesia \\ *Corresponding author: mafruddin.mawon@yahoo.com
}

\begin{abstract}
The squeeze casting process is a metal casting process that requires a tool called extortion. Diess on casting is a component that determines checking performance. Based on this excuse, it is necessary to do a performance analysis (thermal) on squeeze casting to determine components performances. This study aims to determine the performance of the diess in squeeze casting which requires the allocation of heat that occurs and thermal efficiency diess. This research was conducted with a real experimental method with variations in testing at temperatures of $100^{\circ} \mathrm{C}, 200^{\circ} \mathrm{C}, 300^{\circ} \mathrm{C}$, and $400^{\circ} \mathrm{C}$ using Magnesium AZ31 material and combined with aluminum. From the results of research published on the biggest thermal heater that is at a temperature of $400^{\circ} \mathrm{C}$ of $970.68 \mathrm{~W}$ with a thermal efficiency of $18 \%$. While the heat that occurs at a temperature of $100^{\circ} \mathrm{C}$ is $489.25 \mathrm{~W}$ and thermal efficiency is $9 \%$, at a temperature of $200^{\circ} \mathrm{C}$ is $806.28 \mathrm{~W}$ and thermal efficiency is $15 \%$ and at a temperature of $300^{\circ} \mathrm{C}$ is $864.98 \mathrm{~W}$ and thermal efficiency is $16 \%$.
\end{abstract}

Keywords: Temperature, diess, squeeze casting performance.

\begin{abstract}
Abstrak
Proses pengecoran squeeze merupakan proses pengecoran logam yang memerlukan suatu alat yang disebut dengan squeeze casting. Diess pada squeeze casting merupakan komponen yang menentukan kinerja dari squeeze casting. Untuk itu perlu dilakukan analisa kinerja (thermal) diess pada squeeze casting untuk mengetahui kinerja dari komponen tersebut. Penelitian ini bertujuan untuk mengetahu kinerja dari diess pada squeeze casting yang diukur dari besarnya perpindahan panas yang terjadi dan efisiensi thermal diess. Penelitian ini dilakukan dengan metode eksperimen nyata dengan variasi pengujian pada temperatur $100^{\circ} \mathrm{C}, 200^{\circ} \mathrm{C}, 300^{\circ} \mathrm{C}$ dan $400^{\circ} \mathrm{C}$ menggunakan material Magnesium AZ31 dan dipadukan dengan alumunium. Dari hasil penelitian diketahui bahwa perpindahan panas pada heater kebahan yang paling besar yaitu pada temperatur $400^{\circ} \mathrm{C}$ sebesar $970.68 \mathrm{~W}$ dengan efisiensi thermal diess yaitu $18 \%$. Sedangkan perpindahan panas yang terjadi pada temperatur $100^{\circ} \mathrm{C}$ yaitu $489,25 \mathrm{~W}$ dan efisiensi thermal diess yaitu $9 \%$, pada temperatur $200^{\circ} \mathrm{C}$ yaitu $806,28 \mathrm{~W}$ dan efisiensi thermal diess yaitu $15 \%$ dan pada temperatur $300^{\circ} \mathrm{C}$ yaitu $864,98 \mathrm{~W}$ dan efisiensi thermal yaitu $16 \%$.

Kata kunci: Temperatur, diess, kinerja squeeze casting.
\end{abstract}

\section{Pendahuluan}

Proses pengecoran squeeze merupakan suatu proses pengecoran dimana logam cair dibekukan menggunakan tekanan yang tinggi dalam cetakan logam [1]. Proses pengecoran squeeze mampu meningkatkan sifat fisis dan mekanis terutama pada material dengan paduan dasar Aluminium dan
Magnesium [2]. Pada proses pengecoran squeeze hasil dari proses pengecoran dipengaruhi oleh komposisi bahan, semakin banyak penambahan unsur Magnesium pada Aluminium maka nilai kekerasan juga semakin meningkat [3].

Untuk melakukan proses pengecoran squeeze diperlukan suatu alat yang biasa disebit dengan squeeze casting. squeeze casting memiliki komponen utama 
yaitu diess atau cetakan. Di dalam diess terdapat komponen pemanas atau heater yang digunakan untuk memanaskan bahan sampai pada temperatur semi solid (untuk material tertentu) atau pada temperatur diatas $400^{\circ} \mathrm{C}$. Selain pemanas, komponen diess pada squeeze casting yaitu isolator dan penutup. Isolator biasanya terbuat dari pahan dengan nilai konduktifitas termak yang rendah dan berfungsi untuk mengurangi perpindahan panas dari heater kelingkungan. Kinerja dari diess pada squeeze casting dipengaruhi oleh perpindahan panas yang terjadi pada heater kebahan dan panas yang terbuang ke lingkungan.

Perpindahan panas dari heater kelingkungan merupakan kerugian panas yang terjadi pada proses pengecoran logam. Diess pada squeeze casting merupakan komponen yang menentukan kinerja dari squeeze casting. Semakin besar panas yang terbuang maka semakin rendah kinerja dari diess squeeze casting. Untuk itu perlu dilakukan analisa kinerja (thermal) diess pada squeeze casting untuk mengetahui kinerja dari alat diess pada squeeze casting tersebut.

Penelitian ini bertujuan untuk mengetahu kinerja dari diess pada squeeze casting yang diukur dari besarnya perpindahan panas yang terjadi dan efisiensi thermal diess. Dari hasil analisa nantinya dapat digunakan sebagai acuan untuk memperbaiki dan meningkatkan kinerja dari diess pada squeeze casting.

\section{Tinjauan Pustaka}

Pengecoran logam merupakan suatu proses pembuatan benda dengan metode mencairkan logam dan menuangkannya kedalam rongga cetakan. Pengecoran logam dapat dilakukan dengan berbagai macam bahan baku logam seperti besi, baja paduan tembaga dan lain-lain.

Proses squeeze casting atau yang biasa disebut dengan penempaan logam cair (liquid metal forging) adalah suatu proses yang mengkombinasikan keuntungan atau kelebihan dari proses forging dan casting. Perlengkapan proses squeeze casting meliputi: punch, dan ejector pin (direct) serta die, cavity, pouring hole, injection chamber plunger dan gating system (indirect). Pada squeeze casting akan terjadi kontak logam cair dengan permukaan die yang memungkinkan terjadinya perpindahan panas atau heat transfer yang cukup cepat, sehingga menghasilkan struktur mikro yang homogen dengan sifat mekanik yang baik serta produk mendekati ukuran yang sebenarnya (near-netshape). Penelitian pertama tentang pengaruh tekanan terhadap perilaku logam cair (Al-Si) selama proses pendinginan dilakukan oleh Welter pada tahun 1931 [1].

Pada sistem pengecoran istilah pengecoran semi solid adalah proses pengecoran bahan logam dimana dalam proses tersebut material berada pada kondisi fasa cair dan padat atau yang biasa disebut fasa semi solid. Proses pengecoran semi solid mempunyai kelebihan seperti kecepatan proses produksinya yang tinggi dan cacat porositas yang cenderung lebih rendah. Kondisi semi solid pada proses pengecoran ini diperoleh dengan melakukan proses memanaskan diatas temperatur solid. Pada pengecoran semi solid ada beberapa faktor yang mempengarhui hasil dari proses pengecoran itu sendiri, diantaranya yaitu temperatur tuang sangat berpengaruh terhadap struktur mikro serta kekerasan. Penurunan temperatur dapat memyebabkan kenaikan nilai kekerasan [4]. Material Magnesium dan paduanya memiliki potensi besar dalam industri dalam hal proses semi solid [5]. Hasil pengecoran squeeze pada material paduan alumunium dan Magnesium mampu meningkatkan sifat fisik dan mekanisnya [6].

Perpindahan kalor pada heat exchanger dapat didefinisikan sebagai suatu proses berpindahnya suatu energi (kalor) dari saatu daerah kedaerah lain akibat adanya perbedaan suhu atau temperatur pada daerah tersebut. Macam- 
macam proses perpindahan kalor yaitu perpindahan panas konduksi dan perpidahan panas konveksi serta radiasi [7]. Untuk silinder yang panjangya melebihi diameternya dapat diasumsikan bahwa aliran kalor berlangsung menurut arah radial, sehingga koordinat ruang yang kita perlukan untuk menentukan sistem ini hanyalah jari-jari. Luas bidang aliran kalor dalam sistem silinder ini yaitu

$$
A_{r}=2 \pi r L
$$

Sehingga perpindahan panas pada silinder yaitu

$Q_{r}=-k A_{r} \frac{\partial T}{\partial r}$

dimana:

$Q_{r} \quad=$ Perpindahan panas $(\mathrm{W})$

$k \quad=$ Konduktifitas thermal $\left.\left(\mathrm{W} / \mathrm{m}^{\circ} \mathrm{C}\right)\right)$

$A_{r} \quad=$ Luas penampang silinder $\left(\mathrm{m}^{2}\right)$

$\frac{\partial T}{\partial r} \quad=$ Gradient temperatur $\left({ }^{\circ} \mathrm{C}\right)$

$r \quad=$ Jari-jari silinder $(\mathrm{m})$

$L \quad=$ Panjang silinder $(\mathrm{m})$

Dan tahanan thermal pada silinder adalah :

$R_{t h}=\frac{\ln \left({ }^{r_{2}} / r_{1}\right)}{2 \pi k L}$

Dimana :

$R_{t h}=$ Tahanan thermal $\left({ }^{\circ} \mathrm{C} / \mathrm{W}\right)$

$\mathrm{r}_{1}=$ Jari - jari lingkaran dalam $(\mathrm{m})$

$\mathrm{r}_{2} \quad=$ Jari - jari lingkaran luar $(\mathrm{m})$

$\mathrm{k}=$ Konduktivitas thermal $\left(\mathrm{W} / \mathrm{m}{ }^{\circ} \mathrm{C}\right)$

$\mathrm{L} \quad=$ Panjang silinder $(\mathrm{m})$

Sehingga penyelesaian perpindahan panas untuk silinder atau pada heater kebahan yaitu sebagai berikut :

$Q=\frac{\Delta T}{\frac{\ln \left(r^{2} / r_{1}\right)}{2 \pi k L}}$

Dimana :

$\mathrm{Q} \quad=$ Perpindahan panas silinder $(\mathrm{W})$

$\Delta T=$ Perbedaan tempertur $\left({ }^{\circ} \mathrm{C}\right)$

$\mathrm{r}_{1}=$ Jari - jari dalam $(\mathrm{m})$

$\mathrm{r}_{2}=$ Jari - jari luar $(\mathrm{m})$

$\mathrm{k}=$ Konduktivitas thermal $\left(\mathrm{W} / \mathrm{m}{ }^{\circ} \mathrm{C}\right)$

$\mathrm{L} \quad=$ Panjang silinder $(\mathrm{m})$

\section{Metode Penelitian}

Lokasi penelitian dilakukan di Laboratorium Teknik Mesin Universitas Muhammadiyah Metro. Penelitian ini dilakukan dengan metode eksperimen nyata (true experimental research) dengan variasi pengujian pada temperatur $100^{\circ} \mathrm{C}$, $200^{\circ} \mathrm{C}, 300^{\circ} \mathrm{C}$ dan $400^{\circ} \mathrm{C}$ dengan material pengujian menggunakan material Magnesium AZ31 dan dipadukan dengan alumunium. Metode penelitian meliputi tahap persiapan, pembuatan alat, sampai dengan mengujian diess squeeze casting.

Adapun spesifikasi diess pada alat squeeze casting yaitu sebagai berikut:

Tabel 1. Parameter diess squeeze casting

\begin{tabular}{cllr}
\hline No. & \multicolumn{1}{c}{ Bahan } & \multicolumn{2}{c}{ Jenis Bahan } \\
\hline 1. & $\begin{array}{l}\text { Diess } \\
\text { (cetakan) }\end{array}$ & $\begin{array}{l}\text { Menggunakan bahan } \\
\text { Stenless Steel 316 }\end{array}$ \\
\hline 2. & $\begin{array}{l}\text { Semi solid } \\
\text { (pemanas) }\end{array}$ & $\begin{array}{l}\text { Turbuler spiral (in } \\
\text { coloi) }\end{array}$ & baja \\
\hline 3. & Dudukan & $\begin{array}{l}\text { Menggunakan } \\
\text { karbon rendah }\end{array}$ & bajan \\
\hline 4. & Penutup & $\begin{array}{l}\text { Menggunakan } \\
\text { Stenless Steel }\end{array}$ & bahan \\
\hline & $\begin{array}{l}\text { Fiber } \\
\text { glass } \\
\text { wool }\end{array}$ & $\begin{array}{l}\text { Paper } \\
\text { insulation }\end{array}$ & caskets \\
\hline
\end{tabular}

Spesifikasi diess casting pada alat squeeze casting yaitu seperti pada Gambar 1 .

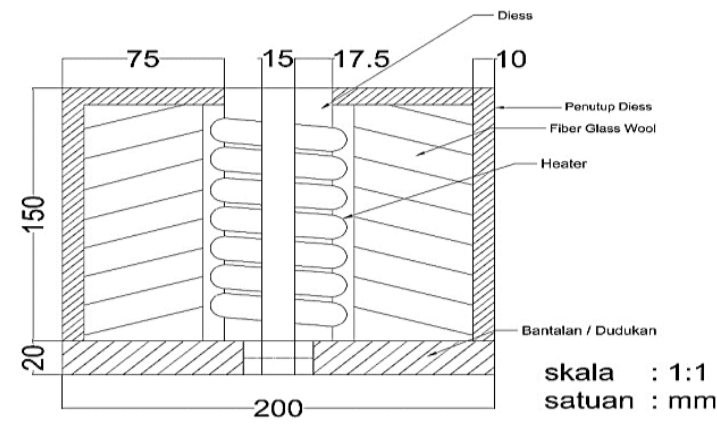

Gambar 1. Diess squeeze casting

Pengujian dilakukan dengan melakukan pemanasan pada material uji selama 15 menit pengujian, yang kemudian dilakukan pengambilan data berupa temperatur pada material uji, temperatur heater, temperatur isolator dan temperatur penutup. 


\section{Hasil dan Pembahasan}

Berdasarkan hasil pengujian dan perhitungan perpindahan panas yang terjadi dari heater kebahan diperoleh data sebagai berikut.

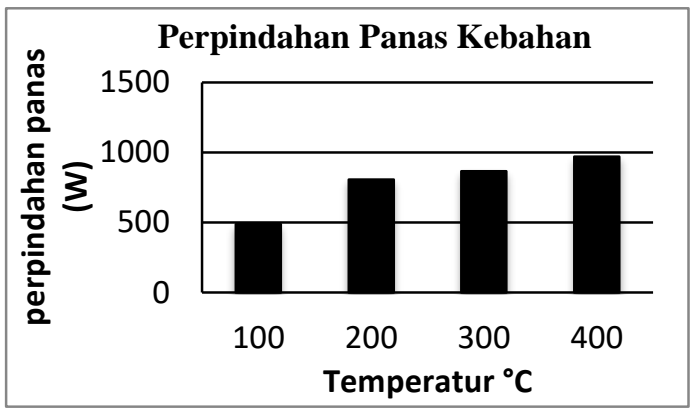

Gambar 2. Perpindahan panas dari heater kebahan

Berdasarkan Gambar 2, perpindahan panas dari heater kebahan dapat diketahui besarnya perpindahan panas yang terjadi dari heater kebahan pada masing-masing temperatur. Perpindahan panas yang terjadi pada temperatur $100^{\circ} \mathrm{C}$ yaitu $489,25 \mathrm{~W}$, pada temperatur $200^{\circ} \mathrm{C}$ yaitu $806,28 \mathrm{~W}$, pada temperatur $300^{\circ} \mathrm{C}$ yaitu $864,98 \mathrm{~W}$ dan pada temperatur $400^{\circ} \mathrm{C}$ yaitu $970,68 \mathrm{~W}$. Fenomena yang terjadi yaitu semakin besar tempeatur pada pada pemanas (heater) maka semakin besar perpindahan panas yang terjadi dari pemanas kebahan uji. Perpindahan panas yang terjadi dari pemanas (heater) kebahan dipengaruhi oleh perbedaan temperatur pada pemanas dan jenis bahan yang digunakan sebagai diess, sehingga semakin besar perbedaan temperatur maka perpindahan panas juga akan semakin besar. Selain itu, penggunaan bahan diess dengan konduktifitas yang tinggi juga akan meningkatkan perpindahan panas yang terjadi dari heater kebahan.

Berdasarkan hasil pengujian dan perhitungan diperoleh besarnya panas yang terbuang melului dinding luar dan penutup pada bagian atas diess atau cetakan yaitu sebagai berikut.

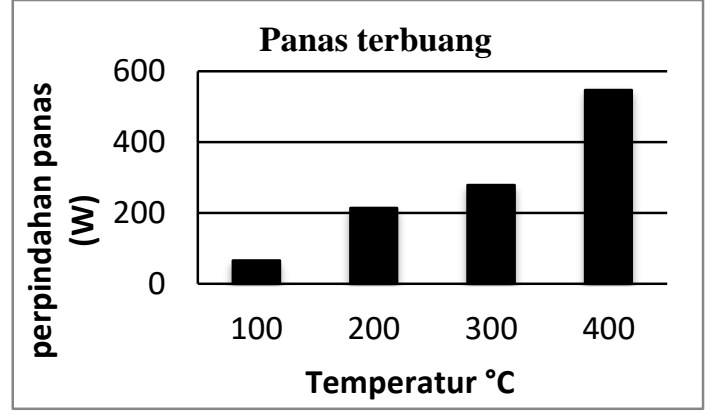

Gambar 3. Panas yang terbuang

Perpindahan panas yang terjadi pada diess tidak hanya perpindahan panas dari heater atau pemanas kebahan, tetapi juga terjadi perpindahan panas dari heater kedinding luar dan penutup pada bagian atas diess.

Berdasarkan Gambar 3, panas yang terbuang melalui dinding dan penutup dapat diketahui besarnya perpindahan panas yang terjadi pada heater kedinding bagian luar dan penutup (panas yang terbuang). Panas yang terbuang pada temperatur $100^{\circ} \mathrm{C}$ yaitu $66,54 \mathrm{~W}$, pada temperatur $200^{\circ} \mathrm{C}$ yaitu $214,22 \mathrm{~W}$, pada tempeatur $300^{\circ} \mathrm{C}$ yaitu $278,29 \mathrm{~W}$ dan pada tempeatur $400^{\circ} \mathrm{C}$ yaitu $546,85 \mathrm{~W}$. Sama halnya dengan perpindahan panas dari heater kebahan, perpindahan panas yang terjadi pada heater kedinding luar dan penutup juga terjadi fenomena semakin besar tempeatur pemanas maka semakin besar perpindahan panas yang terjadi.

Perpindahan panas yang terjadi dari heater kedinding luar dan penutup dipengaruhi oleh perpedaan temperatur antara heater dan tempeatur dinding bagian luar dan temperatur penutup, jenis bahan yang diguanakan serta diameter diess dan penutup. Pada temperatur $400^{\circ} \mathrm{C}$ terjadi panas yang terbuang tertinggi. Hal ini disebabkan perbedaan temperatur antara heater dengan dinding luar dan penutup serta tempeatur lingkungan yang tinggi sehingga mempengaruhi perpindahan panas yang terjadi.

Perpindan panas dari heater kedinding luar diess juga dipengaruhi oleh bahan isolator yang digunakan. Pada penelitian ini bahan isolator menggunakan fiber glass wool yang memiliki nilai 
konduktifitas yang rendah, sehingga besarnya panas yang terbuang disebabkan oleh perbadingan anatara diameter heater dan diameter dinding luar serta ketebalan lapisan isolator.

Pada penelitian ini menggunakan pemanas listrik, dimana daya lisrik untuk pemanas yaitu 5250 Watt. Dari hasil perhitungan diperoleh besarnya efisiensi thermal diess pada alat squeeze casting yaitu sebagai berikut.

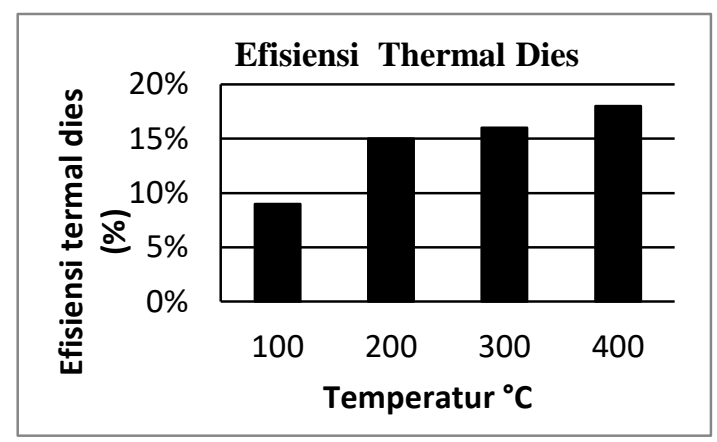

Gambar 4. Efisiensi thermal diess

Berdasarkan Gambar 4, efisiensi thermal diess dapat diketahui kinerja dari diess atau cetakan pada alat squeeze casting. Efisiensi thermal diess pada temperatur $100^{\circ} \mathrm{C}$ yaitu $9 \%$, pada tempetur $200^{\circ} \mathrm{C}$ yaitu $15 \%$, pada temperatur $300^{\circ} \mathrm{C}$ yaitu $16 \%$ dan pada tempeatur $400^{\circ} \mathrm{C}$ yaitu $18 \%$.

Pada temperatur $\quad 100^{\circ} \mathrm{C}$ menghasilkan efisiensi yang paling rendah. Hal ini terjadi karena panas yang diserap bahan sangat kecil sehingga mempengaruhi nilai efisiensi thermal diess. Sedangkan pada temperatur $400^{\circ} \mathrm{C}$ menghasilkan efisiensi thermal yang tertinggi. Perpindahan panas dari heater kebahan pada tempeatur $400^{\circ} \mathrm{C}$ cukup tinggi sehingga efisiensi thermal juga tinggi, meskipun panas yang terbuang pada temperatur ini juga tinggi tetapi masih menghasilkan kinerja yang baik jika dibandingkan dengan temperatur dibawahnya.

Dari hasil penelitian dan perhitungan diketahui bahwa efisiensi thermal diess pada masing-masing variasi temtepatur masih sangat rendah. Efisiensi thermal diess dipengaruhi oleh efisiensi dari heater dan besarnya panas yang terbuang melalui dinding dan penutup. Untuk pemanas perlu digunakan sistem penamas yang memiliki efisinesi yang tinggi sehingga dapat meningkatkan kinerja dari diess.

Efisiensi thernal diess juga dipengaruhi oleh besarnya panas yang terbuang melalui dinding dan penutup. Panas yang terbuang memalui dinding dipengaruhi oleh jenis bahan dan perbandingan diameter heater dan diameter dinding penutup luar diess. Panas yang terbuang melalui dinding masih sangat besar sehingga perlu dilakukan perbaikan pada diess. Perbadingan diameter heater dan diess perlu diperbesar sehingga ketebalan isolator akan bertambah. Dengan penamabahan ketebalan isolator maka perpindahan panas yang melalui dinding akan lebih kecil. Selain itu bahan untuk dinding luar juga harus mempunyai nilai kondukfitas yang rendah untuk memperkecil panas yang tebuang.

\section{Kesimpulan}

Dari hasil penelitian diketahui bahwa perpindahan panas pada heater kebahan yang paling besar yaitu pada temperatur $400^{\circ} \mathrm{C}$ sebesar $970.68 \mathrm{~W}$ dengan efisiensi thermal diess yaitu $18 \%$. Sedangkan perpindahan panas yang terjadi pada temperatur $100^{\circ} \mathrm{C}$ yaitu $489,25 \mathrm{~W}$ dan efisiensi thermal diess yaitu 9\%, pada temperatur $200^{\circ} \mathrm{C}$ yaitu $806,28 \mathrm{~W}$ dan efisiensi thermal diess yaitu $15 \%$ dan pada temperatur $300^{\circ} \mathrm{C}$ yaitu $864,98 \mathrm{~W}$ dan efisiensi thermal yaitu $16 \%$.

\section{Referensi}

[1] Duskriadi dan Soejono Tjiro 2002. PengaruhTekanan Dan Temperatur Die Proses Squeeze casting Terhadap Kekerasan Dan Struktur Mikro Pada Material Piston Komersial Lokal. JurnalTeknikMesin Vol.4,1 Hal 1-5.

[2] Purwanto, H., dkk., 2011. Pengaruh Cetakan Pada Pengecoran Squeeze 
Terhadap Sifat Fisis Dan Mekanis Almunium Daur Ulang (Al64\%Si,93\% Fe). Prosiding Seminar Nasional Sains dan Teknologi ke 2 Tahun 2011 Fakultas Teknik Universitas Wahid Hasyim Semarang.

[3] Cholis, S.N.,dkk. (2013). Pengaruh Penambahan Unsur Magnesium (Mg) Terhadap Kekerasan Dan Struktur Mikro Pada Pengecoran Aluminium. (Doctoral dissertation, Universitas Sebelas Maret).

[4] Chambali, M., dkk., 2013. Pengaruh Temperatur Bahan Terhadap Struktur Mikro Dan Kekerasan Pada Proses Semi Solid Casting Paduan Alumunium Daur Ulang. Momentum, Vol. 9, No. 1, April 2013, Hal. 6-12 ISSN 0216-7395.

[5] Abedi, Hamid Reza,et all. (2010). The semi-solid tensile deformation behavior of wrought AZ31 magnesium alloy. Materials and Design. $\quad 31$. 4386-4391. 10.1016/j.matdes.2010.05.004.

[6] GUO, Z. H., et all. (2012). Optimization of AZ80 magnesium alloy squeeze cast process parameters using morphological matrix. Transactions of Nonferrous Metals Society of China, 22(2), 411418.

[7] Holman, P. Jack, 1997. Perpindahan Kalor. Jakarta: Edisi ke Enam. Penerbit Erlangga. 